\title{
Challenges and strategies of clinical application of CAR-T therapy in the treatment of tumors - a narrative review
}

\author{
Weijing Li ${ }^{1}$, Lili $\mathrm{Wu}^{1}$, Chen Huang ${ }^{1}$, Ruixia Liu ${ }^{1}$, Zheng $\mathrm{Li}^{1}$, Lihong Liu ${ }^{1}$, Baoen Shan ${ }^{2}$ \\ ${ }^{1}$ Department of Hematology, ${ }^{2}$ Cancer Institute, The Fourth Hospital of Hebei Medical University, Shijiazhuang, China \\ Contributions: (I) Conception and design: L Liu; (II)Administrative support: B Shan; (III) Provision of study materials: W Li, L Wu; (IV) Collection \\ and assembly of data: C Huang, R Liu; (V) Data analysis and interpretation: W Li, Z Li; (VI) Manuscript writing: All authors; (VII) Final approval of \\ manuscript: All authors. \\ Correspondence to: Baoen Shan; Lihong Liu. The Fourth Hospital of Hebei Medical University, Shijiazhuang, China. Email: baoenshan@hbydsy.com; \\ $1737024700 @ q q . c o m$.
}

\begin{abstract}
Chimeric antigen receptor T-cell (CAR-T) therapy has achieved good therapeutic efficacy in the treatment of hematological malignancies. In August 2017, Novartis Kymriah (CAR-T cells targeting CD19) was approved by the FDA, indicating the real entry of CAR-T cell therapy into clinical applications and making CAR-T cell therapy the most attractive technology in the field of tumor treatment. In October 2017, the FDA approved the world's second CAR-T cell therapy-Yescarta. The launch of these products has attracted wide attention to CAR-T cell therapy. CAR-T cell therapy has achieved significant effect in the treatment of tumors, however, CAR-T therapy also faces clinical problems, such as cytokine release syndrome (CRS), poor therapeutic efficacy in solid tumors, and high rates of tumor recurrence. At present, the side effects of CAR-T therapy have attracted a large amount of attention, which has resulted in investigations into strategy establishment. With a deepening understanding of CAR-T therapy and the continuous optimization of therapeutic regimens, its toxicity and side effects have been partially controlled. This study set out to analyze the problems in the clinical application of CAR-T therapy encountered in recent years and to introduce corresponding strategies, with the aim of providing a basis of reference for clinicians and scientists in the management of CAR-T therapy in clinical practice and in the CAR-T therapy research.
\end{abstract}

Keywords: Chimeric antigen receptor T-cell (CAR-T); cytokine release syndrome (CRS); solid tumor treatment; tumor recurrence; strategy

Submitted Apr 01, 2020. Accepted for publication Aug 17, 2020.

doi: 10.21037/atm-20-4502

View this article at: http://dx.doi.org/10.21037/atm-20-4502

\section{Introduction}

Chimeric antigen receptor T-cell (CAR-T) therapy is a new type of cell therapy that has received widespread clinical attention and has achieved impressive outcomes with hematological malignancies $(1,2)$. The key point of CAR-T cell therapy is to make $\mathrm{T}$ cells express specially designed CAR through genetic modification, then proliferate in vitro, and then infuse into the patient. Through the CAR specifically binding to the surface antigen of targeted tumor cells, the CART-cell can accurately recognize targeted cells and then kill them to achieve the purpose of treating tumors. The basic structure of CAR includes extracellular domain (including $\mathrm{svFv}_{\mathrm{v}}$ and hinge region), transmembrane domain and intracellular domain. Among them, the scFv in the extracellular domain can specifically bind to tumor antigens, which is the "locator" for CART cells to accurately hit target cancer cells. The transmembrane domain can anchor the CAR on the $\mathrm{T}$ cell membrane and guide CART cells to The "retractor" of the target cell, the intracellular domain is responsible for signal activation and conduction, and is the "signal switch" that enables CART cells to exert their killing function. 


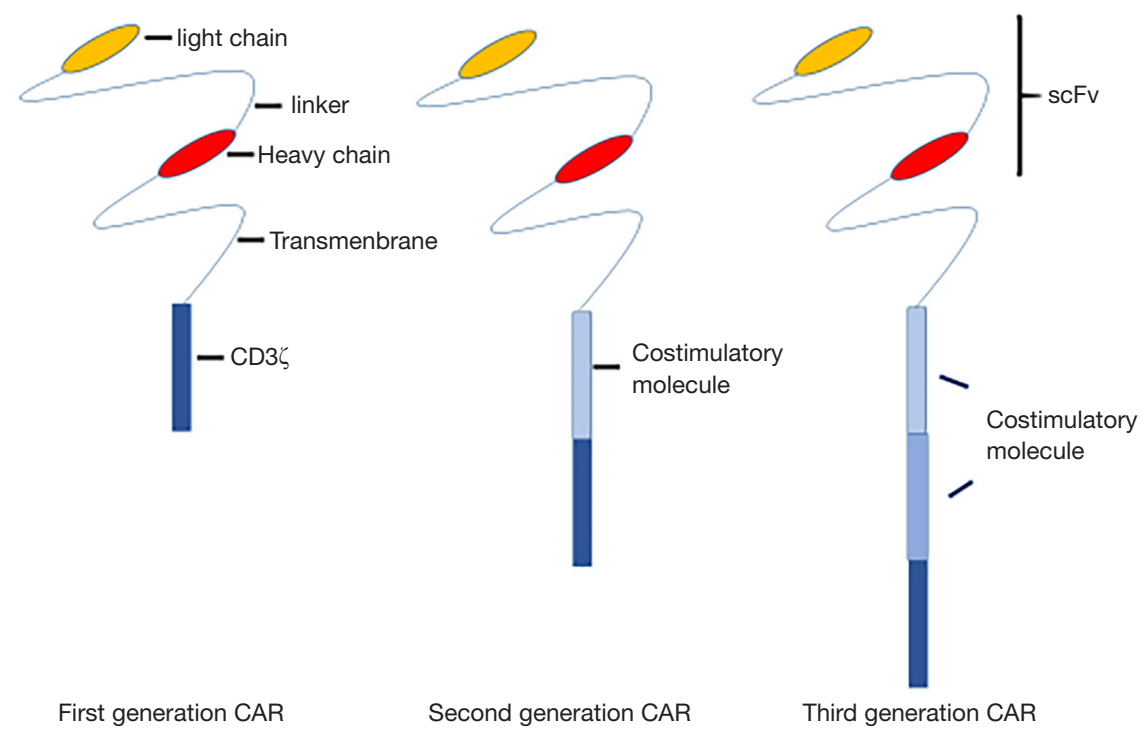

Figure 1 Chimeric antigen receptor (CAR) generations. First generation CARs were composed of the single-chain variable region (scFv) linked to intracellular CD3 zeta $(\zeta)$. Second generation CARs incorporated an intracellular signaling motif from a T-cell costimulatory molecule followed by $\mathrm{CD} 3 \zeta$, while third generation CARs include more than one costimulatory molecule in addition to CD3

So far, there are three generations of CAR (Figure 1). The US Food and Drug Administration (FDA) has approved the marketing of Kymriah (Novanis) and Yescarta as CAR-T drugs for the treatment of hematological malignancies worldwide. Despite CAR-T therapy achieving good outcomes in hematological malignancies, its clinical application still brings multiple problems, such as cytokine release syndrome (CRS), poor efficacy in solid tumors, and a high rate of recurrence. Many problems need to be solved before the use of CAR-T therapy in clinical practice can be a mainstream treatment. As the problems continue to emerge, the corresponding solution strategy seems to be more important. It seems that there are relatively few articles summarizing this, so in this paper, we mainly elucidate the existing problems of CAR-T therapy in clinical practice and propose relevant solutions and strategies.

We present the following article in accordance with the Narrative Review reporting checklist (available at http:// dx.doi.org/10.21037/atm-20-4502).

\section{CRS}

\section{Overview of CRS}

A certain degree of cytokine release is considered as a sign of effective CAR-T therapy; however, the excessive release of cytokines can lead to CRS. Currently, CRS is the most common complication associated with CAR-T therapy (3). Defined as the excessive cascade release of cytokines, including IFN $\gamma$, IL6, IL1, and IL2RA, CRS sees CAR-T cells massively proliferate after contact with tumor antigenbearing cells, producing lethality against tumor cells (4). The consequential "cytokine storm" causes a syndrome leading to successive related activities that inflict damage to the patient's body (5). The clinical manifestations of CRS are diverse, and mainly include high fever, weakness, fatigue, myalgia, nausea, anorexia, tachycardia, hypotension, capillary leakage, cardiac insufficiency, renal damage, liver failure, and diffuse intravascular coagulation. In a study of 30 patients with relapsed/refractory acute lymphoblastic leukemia ( $\mathrm{r} / \mathrm{r}$ ALL) (1), almost all patients had CRS, 8 of whom developed severe CRS after receiving anti-CAR-T19 therapy. Although some patients who experience the abovementioned serious toxic reactions need to be monitored and admitted to the intensive care unit, with the condition even proving fatal for some, in most patients, the symptoms of toxic reactions are controllable. In addition, accurate assessment and timely treatment can attenuate the adverse consequences of immune cell therapy. We would mainly introduce the classification and treatment of CRS and cellrelated encephalopathy syndrome (CRES). 
Table 1 CRS classification criteria

\begin{tabular}{|c|c|c|c|c|}
\hline Institution & Grade 1 & Grade 2 & Grade 3 & Grade 4 \\
\hline CHOP/PENN & $\begin{array}{l}\text { Mild symptoms } \\
\text { (supportive care only) }\end{array}$ & $\begin{array}{l}\text { Moderate symptoms with } \\
\text { some signs of organ } \\
\text { dysfunction (need for } \\
\text { hospital admission for } \\
\text { some IV antibiotics and } \\
\text { monitoring) }\end{array}$ & $\begin{array}{l}\text { Moderate to severe } \\
\text { symptoms with increased } \\
\text { organ dysfunction } \\
\text { (interventions for } \\
\text { hypotension, coagulopathy } \\
\text { \& hypoxia) }\end{array}$ & $\begin{array}{l}\text { Life threatening complications } \\
\text { requiring aggressive } \\
\text { interventions (high dose } \\
\text { vasoactives, mechanical } \\
\text { respiratory support) }\end{array}$ \\
\hline Lee Criteria & $\begin{array}{l}\text { Mild flu-like symptoms } \\
\text { (supportive care only) }\end{array}$ & $\begin{array}{l}\text { Moderate symptoms } \\
\text { requiring intervention: } \\
\text { hypotension responsive } \\
\text { to fluids or low dose } \\
\text { vasoactive, hypoxia } \\
\text { responsive to supplemental } \\
\mathrm{O}_{2} \text {, mild organ dysfunction }\end{array}$ & $\begin{array}{l}\text { Increasing symptomatology: } \\
\text { hypotension necessitating } \\
\text { multiple vasoactives, } \\
\text { hypoxia necessitating } \\
\text { increasing } \mathrm{O}_{2} \\
\text { supplementation ( }>40 \%) \text {, } \\
\text { grade } 4 \text { transaminitis }\end{array}$ & $\begin{array}{l}\text { Life-threatening symptoms } \\
\text { (mechanical respiratory } \\
\text { support, grade } 4 \text { organ } \\
\text { toxicity) }\end{array}$ \\
\hline CARTOX & $\begin{array}{l}\text { Temperature } \geq 38^{\circ} \mathrm{C} \text {. } \\
\text { Grade } 1 \text { organ toxicity }\end{array}$ & $\begin{array}{l}\text { Hypotension responsive } \\
\text { to fluids or low dose } \\
\text { vasoactives. Hypoxia } \\
\text { requiring supplemental } \\
\mathrm{O}_{2}<40 \% \text {. Grade } 2 \text { organ } \\
\text { toxicity }\end{array}$ & $\begin{array}{l}\text { Hypotension requiring } \\
\text { multiple vasoactives. } \\
\text { Hypoxia requiring }>40 \% \mathrm{O}_{2} \text {. } \\
\text { Grade } 3 \text { organ toxicity or } \\
\text { Grade } 4 \text { transaminitis }\end{array}$ & $\begin{array}{l}\text { Life threatening hypotension. } \\
\text { Hypoxia requiring mechanical } \\
\text { respiratory support. Grade } 4 \\
\text { organ dysfunction }\end{array}$ \\
\hline ASBMT & Temperature $\geq 38^{\circ} \mathrm{C}$ & $\begin{array}{l}\text { Temperature } \geq 38{ }^{\circ} \mathrm{C} \text { with } \\
\text { hypotension and/or hypoxia } \\
\text { (not requiring additional } \\
\text { interventions other than } \\
\text { supplemental } \mathrm{O}_{2} \text { by } \mathrm{NC} \text { ) }\end{array}$ & $\begin{array}{l}\text { Temperature } \geq 38^{\circ} \mathrm{C} \text { with } \\
\text { hypotension requiring } 1 \\
\text { vasoactive ( } \pm \text { vasopressin) or } \\
\text { hypoxia requiring high flow or } \\
\text { other non-positive pressure } \\
\text { intervention }\end{array}$ & $\begin{array}{l}\text { Temperature } \geq 38^{\circ} \mathrm{C} \text { with } \\
\text { hypotension requiring multiple } \\
\text { vasoactives or hypoxia } \\
\text { requiring positive pressure }\end{array}$ \\
\hline
\end{tabular}

CRS, cytokine release syndrome.

\section{Classification of CRS}

CRS typically occurs within the first week after CAR-T therapy, reaching its peak within 1 to 2 weeks. Consensus guidelines for scoring CRS, which have not been widely adopted, have been established by multiple groups based on different variables (Table 1) (6-8). To a certain degree, these scoring models can unify institutions and homogeneous groups.

\section{Treatment of CRS}

A strong positive correlation has been reported between the severity of CRS after CAR-T therapy and the levels of CAR-T cells in blood and serum level of IL-6 (9). For patients with moderate to severe CRS, tocilizumab or chimeric anti-IL-6 mAb cetuximab has become the first-choice treatment (10). The timely administration of tocilizumab is recommended for Grade 3 CRS or elderly patients with Grade 2 CRS combined with other diseases, and ultimately aims to avert life-threatening Grade 4 and 5 CRS. In most patients, CRS rapidly degrades after the administration of tocilizumab. Therefore, when the US FDA approved Kymriah, tocilizumab was simultaneously approved to treat CAR-T-induced CRS. Moreover, the application of tocilizumab appears unlikely to affect CAR-T therapy and its clinical efficacy (11), and as a result, the use of tocilizumab is more common than that of cetuximab.

Both CRS and cell immunotherapy-related hemophilic lymphocyte hyperplasia (HLH) can effectively be controlled by glucocorticoids via the suppression of inflammatory 
responses. Data from several clinical trials of CAR-T therapy have shown that glucocorticoids do not decrease the efficacy of CAR-T therapy when used to treat CRS (12). In a Chinese study on the treatment of acute B lymphocytic leukemia (B-ALL) patients, the use of glucocorticoids could significantly reduce severe symptoms of CRS, while eight patients experienced B-ALL recurrence (13). In another study of 30 B-ALL patients who received CAR-T19 (CTL019) therapy, 2 out of 9 patients who received glucocorticoids suffered subsequent recurrence (14). According to the above studies, glucocorticoid exerts inhibitory effects on CAR-T therapy. Therefore, glucocorticoid therapy should only be considered when treatment with anti-IL-6 fails to control the symptoms of CRS.

Therapeutic plasma exchange (TPE) has not been used as the main therapeutic approach for CRS. A small amount of literature has reported that TPE can assist with the rapid clearance of cytokines in plasma and is helpful in treating patients with severe CRS. A 23 -year-old patient with relapsed and refractory B-ALL was reported to exhibit responses typical of CRS, including fever, muscle soreness, and elevated inflammatory cytokines, after the infusion of CAR-T cells. Despite treatment with anti-allergic agents, antipyretic agents, glucocorticoid, and tocilizumab, the patient's CRS symptoms were not effectively controlled and his condition rapidly deteriorated. In the intensive care unit, the patient was treated with 3,000 $\mathrm{mL}$ plasma exchange daily. The patient's CRS-associated symptoms were gradually alleviated, and he was eventually discharged (15). Due to the potential severe complications associated with TPE, it must be performed by experienced medical staff. In cases of CRS and ineffective treatment as well as deteriorated condition, TPE is an alternative solution for CRS after CAR-T therapy (16).

The symptoms of CRS following CAR-T cell therapy are generally diverse and complicated. Medical staff should therefore strive to fully understand and accurately evaluate the unique adverse reactions caused by immunotherapy which tocilizumab and hormones are the two most important agents.

\section{CAR-T therapy in solid tumors}

CAR-T therapy has achieved significant success in treating certain human hematological malignancies, including leukemia and lymphoma (17-21). Although CAR-T therapy was first applied in the treatment of solid tumors, the progress of CAR-T therapy for this purpose has been relatively slow and faces great challenges (22-26).

\section{Causes of poor efficacy of CAR-T in solid tumors}

\section{Heterogeneity of solid tumors}

The membrane protein CD19 on the surface of B-cell leukemia cells is similarly found in hematological malignancies, and is also widely expressed in almost all $\mathrm{B}$-cell leukemia; therefore, CD19-specific CAR-T therapy yields excellent efficacy (1,27-29). However, the heterogeneity of solid tumors stems from their extremely complicated composition from many tumor cells derived from multiple clones. The expression of target antigens on the surface of tumor cells is not completely consistent, making it difficult for a single type of CAR-T cells to kill all tumor cells, which causes difficulty in selecting tumor-specific antigens and also limiting the specificity of CAR-T cells and their extensive application in solid tumors.

\section{Off-target effects}

When targets exist in both tumor and non-tumor tissues, CAR-T cells can clear both tumor cells and normal cells. For instance, CAR-T cells targeting CD19 protein are very effective in identifying and destroying B-cell lymphoma and leukemia cells but can also simultaneously destroy all normal CD19+ B cells in the patient; such events are referred to as off-target effects.

\section{The difficulty faced by CAR-T cells in homing and colonization in tumor tissue}

To reach the tumor cell site, CAR-T cells have to cross the extracellular matrix, and also face unfavorable conditions posed by the immunosuppressive microenvironment. When the CAR-T cells finally reach the tumor cells, they are already reduced in number and activity and possess significantly diminished tumor-killing efficacy. Therefore, by improving their homing ability, the tumor-killing ability of CAR-T cells can be enhanced.

\section{Tumor microenvironment (TME) of solid tumors}

The TME is predominantly in a state of hypoxia and nutritional starvation, which inhibits $\mathrm{T}$ cell proliferation and cytokine production. The efficacy of CAR-T cells, such as prostaglandin E2 (PGE2) and adenosine, may also decrease tumor-derived soluble factors and cytokines. In addition, various immunosuppressive cells, including Regulatory T cells (Tregs), myeloid-derived suppressor cells (MDSCs) and suppressive immune molecules, such as PD- 
L1 and PD-1, also exist in the TME, causing the functions of CAR-T cells to be suppressed upon entering the tumor mass (30). These immunosuppressive mechanisms are the main causes of the formation of the TME and ultimately contribute to the poor therapeutic efficacy of CAR-T cells in solid tumors.

\section{Solutions and strategies for CAR-T therapy in solid tumors}

\section{Selection of specific targets}

The identification and screening of new antigen targets for various solid tumors and the construction of corresponding CAR-T cells are the critical prerequisites for the clinical application of CAR-T in the treatment of solid tumors. Glypican-3 (GPC3) is highly expressed on the surface of liver cancer cells, but its expression is restricted on normal cells (31), making it a promising target for CAR-T therapy in liver cancer. GPC3 CAR-T cells have been shown to exhibit good activation and killing effects on GPC3positive liver cancer cells but exert almost no specific killing effects on liver cancer cells without GPC3 expression (32). Meanwhile, mucin 1 (MUC1) is a transmembrane protein. Wilkie et al. used MUC1 CAR-T cells to target breast cancer cells with MUC1 overexpression (33), and it was confirmed that the growth of xenograft can be significantly inhibited by MUC1-CAR-T cells in breast cancer mouse models.

\section{Promotion of the homing and aggregation of CAR-T cells in tumor tissues}

A recent study found that Runx 3 protein can drive $T$ cells from the lymphatic tissue to reaccumulate in the peripheral and tumor tissues (34). The promotion of Runx3 gene expression has been validated to significantly promote the accumulation of $\mathrm{T}$ cells in tumor tissues and to inhibit tumor growth in a melanoma mouse model. The homing and aggregation of CAR-T cells in tumor tissues also depend on the recognition and binding of chemokine receptors (CCRs) on the surface of $\mathrm{T}$ cells with corresponding chemokines on the surface of tumor cells. The combination of CCRs and corresponding chemokines might facilitate a greater proportion of $\mathrm{T}$ cells to reach the solid tumor. A study by Ahmed et al. showed that in patients with HER2-positive relapsed and refractory sarcoma, 4 out of the 17 evaluable patients treated with HER2-CAR-T therapy were stable within 12 weeks to 14 months. Three patients underwent tumor resection, with one of them exhibiting more than $90 \%$ necrosis. The median overall survival (OS) for all 19 patients who received infusion was 10.3 months (35).

\section{Dual CAR system}

One of the main problems of CAR-T therapy is the identification of an ideal antigen, because most antigens in tumor cells are also present in normal cells of the human body. As a result, in the process of attacking tumor cells, activated $T$ cells can also inflict damage on normal tissues. To this end, two CARs exist on engineered $\mathrm{T}$ cells, and $\mathrm{T}$ cell activation depends on the binding of these two CARs to their specific antigens. That is to say, dual tumor antigen binding with CAR-T cells is required to initiate immune response (36). Therefore, the dual CAR-T strategy renders control over the affinity of the immune response and the prevention of immune-related adverse events. Caruso et al. attempted to generate CAR-T cells from monoclonal antibodies with different affinities, thereby distinguishing malignant tumors from normal cells based on the different densities of EGFR expression (37). In a study on liver cancer in mice, Chen et al. found that dual-targeting CAR-T cells show significantly higher ability in regard to cytokine secretion, proliferation, and anti-apoptosis in vitro (38).

\section{Modification of CAR-T cells}

The precise activity and safety of modified T cells is directly determined by the antigen specificity of the CAR structure. However, the heterogeneity of tumor antigens can lead to ineffective immune surveillance in solid tumors, resulting in refractory and recurrent tumors. Therefore, the expressed specific antigen should be able to clearly distinguish tumor tissues from normal tissues. However, all the above requirements can be effectively overcome through the intrinsic or extrinsic modification of CAR-T cells.

CRISPR/Cas9-mediated genome editing techniques are widely used. Nuclear transfection of CRISPR-Cas9 ribonucleoprotein can destroy $\mathrm{PD}-1$ in CAR-T cells, leading to better tumor controlling effects of anti-CAR-T19 cells in vitro and in subcutaneous xenograft mouse models, and increasing the viability of CAR-T cells (39). CRISPR/ Cas9 technology might also shed novel light on the future application of CAR-T treatment.

\section{CAR-T cell transport}

The effective transport of CAR-T cells from peripheral circulation to the tumor site also determines the effectiveness of CAR-T therapy in solid tumors. We believe that the direct regional delivery of CAR-T cells 
into metastatic organs or spaces would definitely enhance their safety and effectiveness. In addition, a combination of regional CAR-T delivery with an immunosuppressive method can further improve the therapeutic performance of CAR-T in solid tumors. In the mouse model of peritoneal metastasis of colorectal cancer established by Katz et al., the direct peritoneal perfusion of CAR-T cells was shown to be more effective in achieving tumor control than systemic infusion in mice with peritoneal metastasis (40). Other local injections, such as hepatic arterial intubation in liver cancer and intracranial injection in glioblastomas (41) can directly deliver CAR-T cells into the tumor tissue, thereby enhancing the direct tumor killing effect of CAR-T cells.

\section{Tumor recurrence after CAR-T therapy}

\section{Causes of tumor recurrence after CAR-T therapy}

Although CAR-T therapy has demonstrated adequate efficacy in treating tumors, especially hematological malignancies, recurrence is still a problem. Long-term follow-up data shows that patients can still suffer from tumor recurrence even after complete remission (42). In the study, which investigated CD19CAR-T cells in leukemia treatment, most patients could be relieved after treatment, but some patients relapsed after a period of CD19CAR-T treatment, which was mainly caused by the loss of CD19 antigen in some leukemia cells, making recognition for CD19CAR-T cells impossible, thereby resulting in immune escape. Another underlying mechanism of tumor recurrence is the expression of immunosuppressive molecules, including PD-L1, IDO, and adenosine receptors. The combination of PD-L1 from leukemia cells and PD-1 from CAR-T cells, for instance, decreases the function of CAR-T cells (43).

\section{Therapeutic strategies for tumor recurrence after CAR-T therapy}

\section{Multi-target therapy}

The most common cause of tumor recurrence after CAR-T therapy is the loss of CD19, which leads to the proliferation of target-negative cells, causing ineffective CAR-T therapy. Apart from CD19, common surface markers of B-ALL cells include CD20, CD22, and CD123, and by simultaneously targeting multiple targets, the therapeutic effects of CAR-T therapy can be improved. CD19 and CD123 are designed to target leukemia cells, which offers an effective strategy for the treatment and prevention of CD19-negative recurrence (44). However, therapy-associated toxicity calls for special attention and further validation. At present, the effectiveness of multi-target therapy in tumor recurrence is controversial. The therapeutic efficacy and the safety of the treatment need to be verified by subsequent clinical trials.

\section{Blocking immunosuppressive molecules}

The relatively common combination of immunosuppressive molecules PD-L1 and PD-1 can significantly restrict the effectiveness of immunotherapy, thereby impeding the killing function of CAR-T cells in vivo. The combined application of anti-PD-1 monoclonal antibody and CAR-T19 is still under exploration. A study concerning relapsed/refractory B-cell lymphoma showed CAR-T19 therapy to be ineffective in some patients, who were subsequently treated with PD-1 inhibitor pembrolizumab. As a result, PD-1-deficient CAR-T19 cells can enhance CAR-T19 cell-mediated tumor killing in vitro.

Despite continuous breakthroughs in CAR-T therapy, various problems relating to its underlying technology and clinical application still need to be urgently resolved, including the various side effects represented by CRS and unsatisfactory therapeutic efficacy in solid tumors. The continuous development of cell engineering and sitespecific genome editing will strengthen the effectiveness and safety of CAR-T therapy and popularize its clinical application in the treatment of various types of tumor. Although CAR-T cell therapy is still difficult to popularize in clinical applications currently, CAR-T cell therapy is rapidly becoming an effective treatment for many different types of tumors. Through this, hope will be brought to more patients.

\section{Acknowledgments}

Funding: None.

\section{Footnote}

Reporting Checklist: The authors have completed the Narrative Review reporting checklist. Available at http:// dx.doi.org/10.21037/atm-20-4502

Conflicts of Interest: All authors have completed the ICMJE uniform disclosure form (available at http://dx.doi. org/10.21037/atm-20-4502). The authors have no conflicts of interest to declare. 
Ethical Statement: The authors are accountable for all aspects of the work in ensuring that questions related to the accuracy or integrity of any part of the work are appropriately investigated and resolved.

Open Access Statement: This is an Open Access article distributed in accordance with the Creative Commons Attribution-NonCommercial-NoDerivs 4.0 International License (CC BY-NC-ND 4.0), which permits the noncommercial replication and distribution of the article with the strict proviso that no changes or edits are made and the original work is properly cited (including links to both the formal publication through the relevant DOI and the license). See: https://creativecommons.org/licenses/by-nc-nd/4.0/.

\section{References}

1. Maude SL, Frey N, Shaw PA, et a1. Chimeric antigen receptor $\mathrm{T}$ cells for sustained remissions in leukemia. $\mathrm{N}$ Engl J Med 2014;371:1507-17.

2. Johnson LA, June CH. Driving gene-engineered T cell immunotherapy of cancer. Cell Res 2017;27:38-58.

3. Frey N, Porter D. Cytokine release syndrome with chimeric antigen receptor T cell therapy. Biol Blood Marrow Transplant 2019;25:e123-e127.

4. Neelapu SS, Tummala S, Kebriaei P, et al. Chimeric antigen receptor $\mathrm{T}$-cell therapy-assessment and management of toxicities. Nat Rev Clin Oncol 2018;15:47-62.

5. Barrett DM, Teachey DT, Grupp SA. Toxicity management for patients receiving novel T-cell engaging therapies. Curr Opin Pediatr 2014;26:43-9.

6. Lee DW, Gardner R, Porter DL, et al. Current concepts in the diagnosis and management of cytokine release syndrome. Blood 2014;124:188-95.

7. Porter D, Frey N, Wood PA, et al. Grading of cytokine release syndrome associated with the CAR T cell therapy tisagenlecleucel. J Hematol Oncol 2018;11:35.

8. Lee DW, Santomasso BD, Locke FL, et al. ASBMT consensus grading for cytokine release syndrome and neurologic toxicity associated with immune effector cells. Biol Blood Marrow Transplant 2019;25:625-38.

9. Bonifant CL, Jackson HJ, Brentjens RJ, et al. Toxicity and management in CAR T-cell therapy. Mol Ther Oncolytics 2016;3:16011.

10. Turtle CJ, Hanafi LA, Berger C, et al. Immunotherapy of non-Hodgkin's lymphoma with a defined ratio of CD8+ and CD4+ CD19-specific chimeric antigen receptor- modified T cells. Sci Transl Med 2016;8:355ra116.

11. Dholaria BR, Bachmeier CA, Locke F. Mechanisms and management of chimeric antigen receptor T-cell therapyrelated toxicities. BioDrugs 2019;33:45-60.

12. Gardner RA, Finney O, Annesley C, et al. Intent-to-treat leukemia remission by CD19 CAR T cells of defined formulation and dose in children and young adults. Blood 2017;129:3322-31.

13. $\mathrm{Hu} \mathrm{Y}, \mathrm{Wu} \mathrm{Z}$, Luo $\mathrm{Y}$, et al. Potent anti-leukemia activities of chi- meric antigen receptor-modified $T$ cells against CD19 in Chinese patients with relapsed/refractory acute lymphocytic leukemia. Clin Cancer Res 2017;23:3297-306.

14. Sau S, Alsaab HO, Bhise K, et al. Multifunctional nanoparticles for cancer immunotherapy: A groundbreaking approach for re-programming malfunctioned tumor environment. J Control Release 2018;274:24-34.

15. Xiao X, He XY, Li Q, et al. Plasma exchange can be an alternative therapeutic modality for severe cytokine release syndrome after chimeric antigen receptor- $\mathrm{T}$ cell infusion: A case report. Clin Cancer Res 2019;25:29-34.

16. Liu Y, Chen XF, Wang D, et al. Hemofiltration successfully eliminates severe cytokine release syndrome following CD19 CAR- T-cell therapy. J Immunother 2018;41:406-10.

17. Kalos M, June CH. Adoptive T cell transfer for cancer immunotherapy in the era of synthetic biology. Immunity 2013;39:49-60.

18. Restifo NP, Dudley ME, Rosenberg SA. Adoptive immunotherapy for cancer: harnessing the $\mathrm{T}$ cell response. Nat Rev Immunol 2012;12:269-81.

19. June CH, Riddell SR, Schumacher TN. Adoptive cellular therapy: a race to the finish line. Sci Transl Med 2015;7:280ps7.

20. Morrison C. CAR-T field booms as next-generation platforms attract big players. Nat Biotechnol 2015;33:571-2.

21. Zhang $\mathrm{E}, \mathrm{Xu} \mathrm{H}$. A new insight in chimeric antigen receptor-engineered $\mathrm{T}$ cells for cancer immunotherapy. J Hematol Oncol 2017;10:1.

22. Gilham DE, Debets R, Pule M, et al. CAR-T cells and solid tumors: tuning $\mathrm{T}$ cells to challenge an inveterate foe. Trends Mol Med 2012;18:377-84.

23. Yu S, Li A, Liu Q, et al. Chimeric antigen receptor T cells: a novel therapy for solid tumors. J Hematol Oncol 2017;10:78.

24. Beatty GL, O'Hara M. Chimeric antigen receptormodified $\mathrm{T}$ cells for the treatment of solid tumors: 
defining the challenges and next steps. Pharmacol Ther 2016;166:30-9.

25. Jin C, Yu D, Essand M. Prospects to improve chimeric antigen receptor T-cell therapy for solid tumors. Immunotherapy 2016;8:1355-61.

26. Newick K, O'Brien S, Moon E, et al. CAR T cell therapy for solid tumors. Annu Rev Med 2017;68:139-52.

27. Porter DL, Levine BL, Kalos M, et al. Chimeric antigen receptor-modified $\mathrm{T}$ cells in chronic lymphoid leukemia. N Engl J Med 2011;365:725-33.

28. Grupp SA, Kalos M, Barrett D, et al. Chimeric antigen receptor-modified $\mathrm{T}$ cells for acute lymphoid leukemia. $\mathrm{N}$ Engl J Med 2013;368:1509-18.

29. Porter DL, Hwang WT, Frey NV, et al. Chimeric antigen receptor $\mathrm{T}$ cells persist and induce sustained remissions in relapsed refractory chronic lymphocytic leukemia. Sci Transl Med 2015;7:303ra139.

30. Eckstein M, Gupta S. New insights in predictive determinants of the tumor immune microenvironment for immune checkpoint inhibition: a never ending story? Ann Transl Med 2019; 7:S135.

31. Baumhoer D, Tornillo L, Stadlmann S, et al. Glypican 3 expression in human nonneoplastic, preneoplastic, and neoplastic tissues: a tissue microarray analysis of 4, 387 tissue samples. Am J Clin Pathol 2008;129:899-906.

32. Gao H, Li K, Tu H, et al. Development of T cells redirected to glypican-3 for the treatment of hepatocellular carcinoma. Clin Cancer Res 2014;20:6418-28.

33. Wilkie S, Picco G, Foster J, et al. Retargeting of human T cells to tumor-associated MUC1: the evolution of a chimeric antigen receptor. J Immunol 2008,180:4901-9.

34. Milner JJ, Toma C, Yu B, et a1. Runx3 programs CD8+T cell residency in non-lymphoid tissues and turnouts. Nature 2017;552:253.

35. Ahmed N, Brawley VS, Hegde M, et al. Human Epidermal Growth Factor Receptor 2 (HER2)-Specific Chimeric Antigen Receptor-Modified T Cells for the

Cite this article as: $\mathrm{Li} \mathrm{W}, \mathrm{Wu} \mathrm{L}$, Huang C, Liu R, Li Z, Liu L, Shan B. Challenges and strategies of clinical application of CAR-T therapy in the treatment of tumors-a narrative review. Ann Transl Med 2020;8(17):1093. doi: 10.21037/atm-204502
Immunotherapy of HER2-Positive Sarcoma. J Clin Oncol 2015,33:1688-96.

36. Kloss CC, Condomines M, Cartellieri M, et al. Combinatorial antigen recognition with balanced signaling promotes selective tumor eradication by engineered $\mathrm{T}$ cells. Nat Biotechnol 2013;31:71-5.

37. Caruso HG, Hurton LV, Najjar A, et al. Tuning sensitivity of CAR to EGFR density limits recognition of normal tissue while maintaining potent antitumor activity. Cancer Res 2015;75:3505-18.

38. Chen C, Li K, Jiang H, et al. Development of T cells carrying two complementary chimeric antigen receptors against glypican-3 and asialoglycoprotein receptor 1 for the treatment of hepatocellular carcinoma. Cancer Immunol Immunother 2017;66:475-89.

39. Morgan MA, Schambach A. Chimeric antigen receptor T cells: extending translation from liquid to solid tumors. Hum Gene Ther 2018;29:1083-97.

40. Katz SC, Point GR, Cunetta M, et al. Regional CAR-T cell infusions for peritoneal carcinomatosis are superior to systemic delivery. Cancer Gene Ther 2016,23:142-8.

41. Brown CE, Alizadeh D, Starr R, et a1. Regression of glioblastoma after chimeric antigen receptor T-cell therapy. N Engl J Med 2016;375:2561-9.

42. Wang J, Hu YX, Huang H. Acute lymphoblastic leukemia relapse after CD19-targeted chimeric antigen receptor $\mathrm{T}$ cell therapy. J Leukoc Biol 2017;102:1347-56.

43. Cherkassky L, Morello A, Villena-Vargas J, et al. Human CAR T cells with cell-intrinsic PD-1 checkpoint blockade resist tumor-mediated inhibition. J Clin Invest 2016;126:3130-44.

44. Ruella M, Barrett DM, Kenderian SS, et al. Dual CD19 and CD123 targeting prevents antigen-loss relapses after CD19-directed immunotherapies. J Clin Invest 2016;126:3814-26.

(English Language Editor: J. Reynolds) 